\title{
Servant leadership, team-based learning and hope and optimism: A sectoral comparative study
}

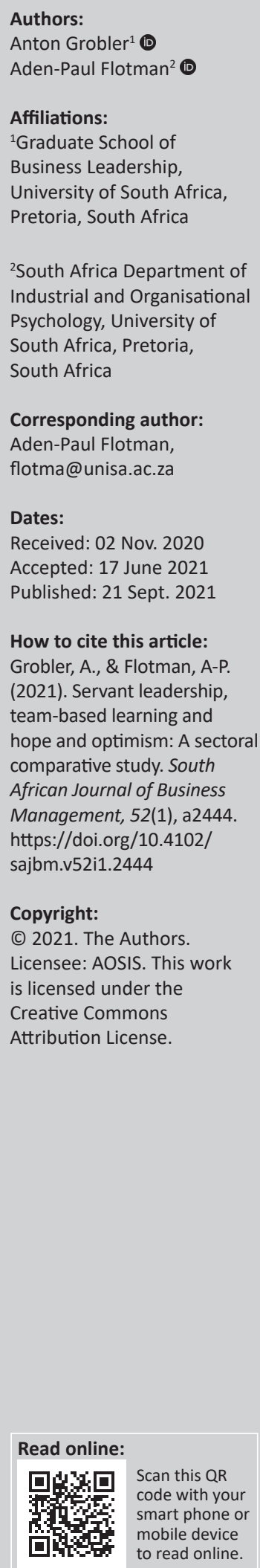

Purpose: This is an era of unprecedented turbulence. The current coronavirus disease 2019 (Covid-19) global pandemic testifies to this turmoil as, daily, the unknown dynamically unfolds. It is important during challenging times like these that leadership and organisational response enhance a shared positive vision for the future of humanity. This study aimed at determining the role played by servant leadership (SL) in promoting employee well-being, specifically, a positive future expectation in terms of hope and optimism $(\mathrm{H} \& \mathrm{O})$, as well as the impact that team-based learning (TBL) has on this relationship, and whether this is the same for both the private and public sectors.

Design/methodology/approach: This study employed an empirical paradigm, using a crosssectional design and quantitative analysis. The total sample consisted of 1560 participants, with 780 employed in the private and public sector, respectively.

Findings/results: The results suggest that both SL and TBL have a significant impact on employees' $\mathrm{H} \& \mathrm{O}$, with TBL being a mediating variable and with stronger relationships reported for the private sector. Technically, the TBL instrument employed was validated for South African use and the study included a statistical assessment of common method bias, which was found not to skew the results.

Practical implications: This study provides further empirical evidence that SL is positively associated with $\mathrm{H} \& \mathrm{O}$. Secondly, the future-mindedness and future-orientation of $\mathrm{H} \& \mathrm{O}$ could stimulate adaptive responses during this time of uncertainty and turmoil. Thus, $\mathrm{H} \& \mathrm{O}$, as potential resilience factors, could generate resilience by harnessing opportunities and setbacks both during the Covid-19 pandemic and in its aftermath.

Originality/value: The practical value of this article is in the empirical evidence that both the leaders and the organisation have an impact on the employees' wellness and positive work attitudes.

Keywords: employee well-being; hope and optimism; sectoral comparison; servant leadership; team-based learning.

\section{Introduction}

Everybody loves a good story! An energising atmosphere is created when there is reason for hopeful expectancy (Lewis, 2019; Schiavon, Marchetti, Gurgel, Busnello, \& Reppold, 2017). There is something magical about an epic comeback story or an intriguing situation in which the odds have been beaten. Human beings want to be associated with achievement, success and positivity (Cvitanovic \& Hobday, 2018; Seligman, 2008). Countries, including South Africa, are no different. However, we live in a world where a great deal of space is created for negativity - daily reports of moral ineptitude (Bergh \& Geldenhuys, 2014; Flotman, May, \& Cilliers, 2019) and ethical bankruptcy (Diamond, 2016), as well as depressing levels of inequality and poverty, leadership derailment and emotional toxicity (Mihalits \& Codenotti, 2020; Petriglieri, 2020) have become a pervasive phenomenon.

South Africa often features in global newspaper headlines, but for the wrong reasons - the Eskom energy crisis and systemic corruption, racial strife and ever-more State-owned Enterprise (SOE) bail-outs, gender-based violence and service delivery protests, to mention just a few (Deloitte, 2019). The national euphoria surrounding South Africa's recent triumph at the Rugby World Cup in Japan was emblematic of a country thirsting for hope and gave reason for optimism. The South African rugby team's rallying cry at the tournament, through the slogan \#strongertogether, was perhaps an expression of an unconscious desire for hope, national cohesion and national pride as a country within a community of nations. The reality is, however, that South Africa, like so many other countries across the globe, is under lockdown because of the coronavirus disease 2019 (Covid-19) pandemic, impacting on individuals' future expectations, including hope and optimism (H\&O). 
With global volatility and digital technologies increasingly on the rise, we are of the view that organisational psychology scholars have been compelled to rethink their deeply held ontological and epistemological assumptions about how we relate to ourselves, to others and to the organisational environment as systems continue to impact each other. It is further important to accept that these organisational systems (context) differ from one organisation, from one industry, and from one sector to another (Haranath, 2017; Ospina, 2016).

Emanating from this development, and regardless of the context, an additional challenge is that digital and team-based learning (TBL) have become the new normal (Vanacker \& Heider, 2018). Organisations are not always ready and committed to embrace this technological challenge within a new digital knowledge-based economy. Our VUCA (volatility, uncertainty, complexity, ambiguity) environment calls for effectivecompassionateleadership and agile, multidisciplinary work-teams for individuals and organisations to become future-fit (Mcafee, Doubleday, Geiger, \& Connell, 2019). In the face of this enormous challenge, employees and leadership often become despondent. Consequently, the purpose of this study was to determine the relationship between servant leadership (SL) and a positive future expectation (from now on referred to as $\mathrm{H} \& \mathrm{O}$ ) in the workplace, as well as the impact that TBL has on this relationship. It is postulated that both SL and TBL could have a decisive influence on individual behaviour and attitudes, particularly within the context of the South African collectivistic culture and the Ubuntu leadership and organisational philosophy (Grobler \& Flotman, 2020). According to a recent study by Eva, Robin, Sendjaya, Van Dierendonck and Liden (2019) organisations that implement SL practices (e.g. Starbucks, Southwest Airlines, RitzCarlton, ServiceMaster, Zappos.com, Container Store, Intel, Marriott) continue to flourish, propelling research into SL. The value of this study lies in its contribution to examining the role and importance of leadership (specifically SL) in respect of $\mathrm{H \& O}$, and - within the collectivistic nature of the South African context - the mediating role of the collectivistic construct of TBL. This study contributes to the academic and organisational psychology domain through the validation of Bresó, Garcia, Latorre and Peiró (2008) TBL instrument within the South African context. The emergence of the Fourth Industrial Revolution, with its subsequent emphasis on TBL, means that the need exists for a valid measure in organisational settings. The investigation into the transferability of the instrument (from a relatively homogeneous population in Spain to the diverse, multi-lingual context of South Africa) was deemed necessary, not only because of ethical, but also scientific reasons (Grobler \& Mathafena, 2020). Practically, the value of this study lies in its recommendations to improve the wellbeing of employees, specifically in terms of a positive future expectation $(\mathrm{H} \& \mathrm{O})$, as an organisational attempt to contribute towards the building of thriving workplaces, flourishing employees and future-fit organisations.

The following section describes the theoretical foundations of SL, followed by its relationship with TBL, as well as employee well-being in the form of $\mathrm{H} \& \mathrm{O}$.

\section{Literature review The essence of servant leadership}

The primary intent of the leader is what distinguishes SL from other leadership approaches (Sendjaya \& Sarros, 2002; Sendjaya, Sarros, \& Santora, 2008). The essence of SL is to serve the good of the whole (Eva et al., 2019), an authentic care for others, including a matured sense of integrity (Parris \& Peachey, 2013). Servant leadership accentuates the development of followers and places a strong emphasis on ethics and morality (Wong \& Page, 2003). Servant leadership theory emanates from the work of Greenleaf (1977). The theory advocates that effective leadership is reflected when the leader's primary motivation is to serve others first. In doing so, the leader places the well-being of followers, in terms of their needs, expectations and aspirations, above that of the leader (Chen, Zhu, \& Zhou, 2015; Laub, 2004). Through this primary intent, service to others is rendered by conscious choice (Greenleaf, 1977). The servant leader is thus animated with a genuine concern to be at the service of others, and seems to be extremely relevant within the African leadership philosophy of Ubuntu (Grobler \& Singh, 2018).

Another major contribution to SL came from Patterson (2003) who developed the central value system of a typical servant leader. The constructs in Patterson's (2003) model comprise Agápao love, altruism, empowerment, humility, service, trust, and vision. She defines servant leaders as those whose primary focus is on their followers, with organisational concerns on the periphery (Patterson, 2003). Thus, stewardship is located at the centre of leadership (Van Dierendonck \& Nuijten, 2011). Spears (2010) later proposed several characteristics of the servant leader, namely awareness, building community, conceptualisation, commitment to the growth of people, empathy, foresight, healing, listening, persuasion and stewardship. The outcome of this authentic concern to be at the service of others is follower satisfaction, the enhancement of the common good and an overall commitment to individual and organisational service. In an attempt to provide more conceptual clarity, Eva et al. (2019, p. 140-169) recently defined SL as a 'holistic leadership approach that engages followers in multiple dimensions (e.g. relational, ethical, emotional, spiritual), such that they are empowered to grow into what they are capable of becoming'. This is not a total distinct concept, as it is closely related to the Ubuntu / Afrocentric leadership, as reported by Grobler and Singh (2018).

Table 1, reflects the evolution of these SL constructs.

\section{Team-based learning and serving others with a positive state of mind}

Positive mindsets have always been linked with enhanced well-being and successful coping, while hopelessness and despair have been associated with non-coping and ill-health. It has been asserted that servant leaders focus on the needs, dreams and aspirations of their followers (Grobler \& Joubert, 2020). It is therefore likely that this primary intent of the 
TABLE 1: Servant leadership - Dominant evolutionary constructs.

\begin{tabular}{|c|c|}
\hline Author & Constructs \\
\hline Graham (1991) & Inspirational, moral. \\
\hline Spears (1998) & $\begin{array}{l}\text { Awareness, conceptualisation, commitment, } \\
\text { community building, empathy, listening, } \\
\text { healing, persuasion, foresight, stewardship. }\end{array}$ \\
\hline Farling, Stone and Winston (1999) & Vision, influence, credibility, trust, service. \\
\hline Patterson (2003) & $\begin{array}{l}\text { Agápao love, humility, altruism, vision, trust, } \\
\text { empowerment, service. }\end{array}$ \\
\hline Dennis and Bocarnea (2005) & $\begin{array}{l}\text { Empowerment, trust, humility, Agápao love, } \\
\text { vision. }\end{array}$ \\
\hline $\begin{array}{l}\text { Liden, Wayne, Zhao and Henderson } \\
\text { (2008) }\end{array}$ & $\begin{array}{l}\text { Empowering, helping, subordinates grow } \\
\text { and succeed; putting subordinates first, } \\
\text { emotional healing, conceptual skills, } \\
\text { creating value for community, behaving } \\
\text { ethically. }\end{array}$ \\
\hline Sendjaya et al. (2008) & $\begin{array}{l}\text { Transforming influence, voluntary } \\
\text { subordination, authentic self, transcendental } \\
\text { spirituality, covenantal relationship, } \\
\text { responsible morality. }\end{array}$ \\
\hline Van Dierendonck and Nuijten (2011) & $\begin{array}{l}\text { Empowerment, humility, standing back, } \\
\text { authenticity, forgiveness, courage, } \\
\text { accountability, stewardship. }\end{array}$ \\
\hline
\end{tabular}

Note: Please see the full reference list of the article, Grobler, A., \& Flotman, A-P. (2021). Servan leadership, team-based learning and hope and optimism: A sectoral comparative study. South African Journal of Business Management, 52(1), a2444. https://doi.org/10.4102/sajbm. v52i1.2444, for more information.

leader would create and nurture a team atmosphere conducive to these being fulfilled. Servant leadership builds a sense of social identity in the followers of those practising it (Chen et al., 2015) and creates teams reminiscent of the kinship found in hunter-gatherer societies as team members assist and collectively build the capacity of others (Yoshida, Sendjaya, Hirst, \& Cooper, 2014). Barsade (2002) demonstrated that teams that are exposed to positive emotions are characterised by enhanced performance and cooperation and less group conflict. Furthermore, studies also suggest that team commitment and performance increase when the psychological capital, including $\mathrm{H} \& \mathrm{O}$ of the team, is nurtured (Luthans, Norman, Avolio, \& Avey, 2008). Senge (1990) has always maintained that teams are the essential learning unit in all organisations. From a collective, African perspective, it is argued that TBL has become an essential tool to deal with a dynamically changing environment, specifically now during the global challenge of Covid-19. Teams are a strategic unit in pursuit of organisational excellence (Senge, 1990; Van Offenbeek, 2001; Yeo, 2003), and it is through team learning that the organisation is able to maintain its relevance and competitiveness in a changing world (Edmonson, 2002).

One of the earliest definitions viewed team learning as a process of knowledge generation (framing and reframing) and that it is a process through which knowledge is created for its members, the system, and others (Kasl, Marsick, \& Dechant, 1997, p. 229). Later, the definition evolved through an emphasis on the data management, adjustment and improvement outcomes of TBL (Edmonson, 1999) as an ongoing process of reflection, action and reflection again. Van Offenbeek's (2001) conceptualisation is informed by information processing theory and sense-making. She defines team learning as 'an iterative team process'; this information is: (1) 'acquired, (2) distributed, (3) interpreted, and (4) stored and retrieved, leading to change in the team's potential behaviours' (p. 305). Thus, in this definition, the structural and interpretive processes are accentuated. Finally, Ellis et al. (2003) identified the outcome of team learning as the evolution of the team's (collective) knowledge and skill level, which is enabled by the shared experiences of individual team members. It is by reflecting on experiences that learning is unleashed at both the individual and team levels. Thus, for team learning to occur, certain activities must be carried out by the team on a regular basis to improve functioning by acquiring certain competencies - these activities are: continuous improvement seeking, dialogue promotion, collaborative learning (Bresó, Garcia, Latorre, \& Peiró 2008), all of which are elements of Ubuntu or Afrocentric leadership, as postulated by Grobler and Singh (2018).

\section{Hope and optimism inspire team collaboration}

Over the last few decades, the constructs of $\mathrm{H} \& \mathrm{O}$ have received increasing attention. It has been shown that $\mathrm{H} \& \mathrm{O}$ are distinct constructs and follow different pathways to positive outcomes. Hope is simultaneously a positive feeling and motivational state, which emanates from the belief that one has agency (i.e. energy that is required) and pathways (i.e. the behavioural means) needed to attain one's goals (Bailis \& Chipperfield, 2012; Mcafee et al., 2019). In Snyder's (2002) theory of hope, people with high hope seem to have more specified routes to accomplish their goals, and frequently remind themselves that they can and will attain their goals. Furthermore, Snyder's theory is distinct in that it provides a detailed account of cognitive processes involved in hopeful thinking and the avenues to attain specified goals. Optimism refers to the extent to which one expects desired outcomes to be realised in future (Bailis \& Chipperfield, 2012). When perceived as a character strength, optimism is a relatively consistent and enduring approach to diverse life situations (Huen, Ip, Ho, \& Yip, 2015). Optimistic individuals perceive challenging events as temporary setbacks.

Individuals have $\mathrm{H} \& \mathrm{O}$ when they not only expect the best in the future, but also actively work towards achieving the best by consistently applying sensible actions. It has been reported that optimistic individuals experience better moods, are more persevering and experience better physical health (Seligman \& Csikszentmihalyi, 2000). Hope has also been associated with increased well-being, lower anxiety and depression symptoms, and with positively coping with cancer (Ebright \& Lyon, 2002; Felder, 2004; Rajandram et al., 2011), as well as with buffering individuals against psychopathology and suicidality (Anestis, Moberg, \& Amau, 2014). However, there has been increasing caution that $\mathrm{H} \& \mathrm{O}$ should not be unrealistic and illusionary (Johns \& Jacquet, 2018). Blind optimism leads to fantasy when resolute efficacy is required in the face of unprecedented ambivalence and uncertainty (Swim, Geiger, Sweetland, \& Fraser, 2018).

Hope and optimism (as a positive future orientated construct), thus, refer to an individual's future-mindedness and future-orientation as regards the successful outcome of future endeavours (Peterson \& Seligman, 2003). As such, both are regarded as characteristics of psychological health and well-being and, when individuals have positive expectations about the future, it is likely that they will engage 
in adaptive responses to both the opportunities and challenges presented by life (Bailis \& Chipperfield, 2012). People who are hopeful and optimistic tend to redouble their commitment in the face of problems and setbacks. This further suggests that these individuals have access to effective coping mechanisms. Hope can also galvanise action on shared goals (Luthans et al., 2008), improve group performance and engage people to collaborate more strategically (Cvitanovic \& Hobday, 2018; Johns \& Jacquet, 2018), which is relevant to the focus of this study. In Bailis and Chipperfield's (2012) review of the H\&O literature, they conclude that small differences in thinking can make a huge difference in adaptive outcomes and that, when individuals feel invested in the future, they tend to take better care of themselves in the present. Thus, $\mathrm{H} \& \mathrm{O}$ could be used as resilience factors to reduce the negative impact of hopelessness and pessimism.

\section{The relationship among the three variables}

A recent study by Bouzari and Karatepe (2017), revealed that SL fosters salespeople's psychological capital, which includes $\mathrm{H} \& \mathrm{O}$ as subdimensions. These employees displayed reduced lateness attitude and expressed an increased intent to remain with the participating organisation. Furthermore, they also have favourable perceptions of service-sales ambidexterity and exhibit service-oriented organisational citizenship behaviours at higher levels. Davis (2018), in a later study, arrived at a similar conclusion, noting that there is a positive relationship between SL and psychological capital and its subdimensions. In a related study, Song, Park and Kang (2015) demonstrated the mediating role of knowledgesharing climate in the relationship between SL and team performance. Servant leadership seems to stimulate teambuilding and team cohesion and an orientation to collectively build team capacity (Yoshida et al., 2014). Teams that experience positive emotions also perform better and seem to cooperate better (Barsade, 2002). Finally, hope can galvanise action to implement shared goals, thereby enhancing team performance (Cvitanovic \& Hobday, 2018).

This study is based on the social learning (Bandura, 1977) and social exchange theories (Blau 1964). These theories suggest that the perception of leadership (as well as team members) has an influence on employee behaviour because of its role modelling and reciprocal effect. Employees will imitate the behaviour of leaders and effective and prominent group members, and will return the goodwill (reciprocate) through positive work attitudes and behaviour.

\section{A cross-sectoral study}

It was deemed necessary to conduct the study across both the private and public sectors and it is thus a sectoral comparison, as recommended by Haranath (2017), Orazi, Turrini and Valotti (2013), Ospina (2016) and Uhl-Bien, Maslyn and Ospina (2012). This is grounded in the seminal work of Hersey and Blanchard (1969) and House (1971) who postulated that organisational differences are often the result of differences in context in which the organisation operates. This seminal work has more recently been supported by various scholars, such as Bedi, Alpaslan and Green (2016), Haranath (2017), Khuntia and Suar (2004), Orazi et al. (2013), Ospina (2016), Uhl-Bien et al. (2012) and Wallace and Tomlinson (2010). For the purposes of this study, it is argued - in line with Altwater and Wright (1996) and Hansen and Villadsen (2010) - that the nature and magnitude of leadership must be investigated across different contexts, in this case the private and public sectors. They are of the opinion that leaders in the public sector find it more challenging to fulfil their leadership role because of what they refer to as leadership constraints. These constraints are often the result of the bureaucratic rules and regulations dictating the functional and operational environment of the public sector, which, it is assumed are less applicable to the private sector. It is therefore argued that sector may not only impact on the perceptions of SL, TBL and H\&O, respectively, but also on the nature of the relationship between them.

\section{Purpose and objectives of this study}

The purpose of this study was to determine the relationship between SL and H\&O in the workplace, and the impact that TBL has on this relationship (as mediator), and whether this is the same for both the private and public sectors. It is, thus, a sectoral comparison. This study consists of five objectives. The first objective was to define the constructs and to explain the relevance of each construct within the broader study. The second objective was to validate the TBL instrument within the South African context, as such validation had not yet taken place. The third and main objective, which is directly linked to the purpose of the study, was to empirically determine the relationship between SL and $\mathrm{H} \& \mathrm{O}$, with the possible mediating effect of TBL. The fourth objective was to determine whether sector (private or public) has an impact on these relationships. The fifth and final objective was to make recommendations to improve the $\mathrm{H} \& \mathrm{O}$ of employees through the enhancement of the perceived SL and TBL.

\section{Method \\ Research design}

This study employed an empirical paradigm, using a crosssectional design and quantitative analysis.

\section{Sample}

Participants were employees of 26 organisations and were comprised of 13 from the private sector and 13 from the public sector, respectively. Organisations were identified by the co-researchers based on availability and proximity, and 60 employees were selected purposively from each of the organisation to participate in this study, with the only inclusion criteria of proficiency in English. The organisations gave written permission to conduct the study. The name lists of employees were provided by the respective human resource departments. Participants gave consent, as stipulated in the ethical clearance process. Ethical clearance was granted by the university. The fieldwork was done by 26 
co-researchers (students) working on a larger project towards completion of their Master of Business Administration (MBA) and Master of Business Leadership (MBL) qualifications.

The total sample consisted of 1560 participants, 780 from each sector. Males reported a slightly higher representation (54.7\%) compared to females $(45.3 \%)$. The mean age of the respondents was 38.21 years (standard deviation $[\mathrm{SD}]=8.70$ ), with the mean period that the respondents had worked in the specific organisation being 7.87 years $(\mathrm{SD}=5.89)$. The participants, in terms of age and tenure, were of sufficient experience to provide an accurate assessment of their perceptions of the constructs being measured.

\section{Measuring instruments Servant leadership}

The 7-item SL questionnaire (SLQ7), developed by Liden et al. (2008), was used to measure SL. To determine the structural validity of the instrument for the South African population, Grobler and Flotman (2020) confirmed the unidimensional nature of the original SLQ7. A typical item of the SLQ7 reads 'My leader can tell if something work-related is going wrong' (item 1). The SLQ7 uses a 7-point Likert scale, ranging from strongly disagree (1) to strongly agree (7). Liden et al. (2015) reported acceptable reliabilities of 0.80 , 0.81 and 0.89 across three independent samples for the SLQ7, while Grobler and Flotman (2020) reported a Cronbach's alpha coefficient of 0.88 and acceptable confirmatory factor analysis (CFA) results $\left(\chi^{2} / d f=2.76\right.$, Comparative Fit Index $[C F I]=0.99$, Root Mean Square Error of Approximation [RMSEA] $=0.032)$, as well as convergent validity.

\section{Team based learning}

The TBL instrument was developed by Bresó et al. (2008). It consists of four dimensions, namely, continued improvement philosophy; dialogue promotion and open communication; collaborative learning; and strategic and proactive leadership that promote learning. Typical items of the four dimensions read: 'Mistakes are openly discussed in order to learn from them'; 'Different points of view are expressed openly and sincerely'; 'We learn from each other', and 'Our boss continuously looks for learning opportunities for him/herself or any team member', respectively. It uses a 6-point Likert scale, ranging from strongly disagree to strongly agree. Bresó et al. (2008), drawing from their Spanish sample, reported acceptable reliabilities for each of the factors, ranging from 0.89 to 0.91 , as noted. Because of the fact that this instrument is the only one used in this study that has not been validated for the South African population, its validation formed part of the study.

\section{Hope and optimism}

Grobler and Joubert (2018) isolated a composite factor called $\mathrm{H} \& \mathrm{O}$, after validating the Psychological Capital (PsyCap) instrument originally developed by Luthans, Youssef and Avolio (2007). Hope and optimism is measured by seven items, using a 6-point Likert scale, ranging from Strongly disagree to Strongly agree, with a typical item reading 'At the present time, I am energetically pursuing my work goals'. Grobler and Joubert (2018) reported a Cronbach alpha coefficient of 0.85 .

\section{Marker variable - Social desirability}

The marker variable (MV) used in this study is SD, measured by six items, based on the original version of the MarloweCrowne SD Scale (Crowne \& Marlowe, 1960), and shortened to a 10-item instrument by Strahan and Gerbasi (1972). Three items each measured the thinking and feeling dimensions, respectively. A 5-point Likert scale, ranging from 'not at all' to 'to a very great extent' was used. A typical item from the thinking and feeling dimensions read 'I'm always willing to admit it when I make a mistake', respectively.

\section{Statistical analysis}

The Statistical Package for the Social Sciences (SPSS version 25) and Analysis of Moment Structures (AMOS), version 25 (IBM, 2017), were used to analyse the data. The distribution of the data was assessed by means of descriptive statistics.

The significance of the mean differences between the two sectors was determined by the use of $t$-tests, with the Levene's test to assess whether equal variances can be assumed (significant value is $>0.05$ ). The practical significance of the differences was determined with Cohen's $d$. Values of 0.15 , 0.30 and 0.50 were interpreted as of small, medium and large effect, respectively (Pallant, 2016). Pearson's product moment correlations were used to determine the strength of the relationship between the constructs. Correlations of 0.30-0.69 and 0.70 and higher are regarded to be moderate and strong, respectively. Below 0.30 is regarded to be weak (Pallant, 2016). Differences in the strength of the relationship between the variables as reported for each of the sectors were determined with z-observed values following a Fisher r-to-z transformation. Interpretation was based on the z-observed value, with the difference in the correlations deemed to be statistically significant when greater than 1.96 or smaller than 1.96 .

Hierarchical regression analysis was used to determine the amount of variance explained in the predicted variable by the predictor variables. The practical significance of the regression analysis is regarded to be small with an $f^{2}$ value of 0.15 , medium with a value of 0.35 and large with a value of $>0.35$ (Cohen, 1988).

The Hayes' PROCESS macro(four) for SPSS (Hayes \& Preacher, 2014) was used to assess the possible mediation effect of TBL on the relationship between SL and H\&O. Structural equation modelling was conducted to assess the model fit, specifying the relationships of the constructs theoretically. The guidelines of Hu and Bentler (1999) and Schumacker and Lomax (1996) were used to assess the goodness of fit criteria of the chi-square $\left(\chi^{2}\right)$, ratio of chisquare to its degrees of freedom $(d f)$, Incremental Fit Index (IFI), Tucker Lewis Index (TLI), CFI, and RMSEA. The 
analysis was performed on the total dataset, as well as the sectors independently (each consisting of an equal number of 780 respondents). The purpose of this was to determine the similarities and differences regarding the variables, as well as relationships between the variables, from a sectoral perspective.

The model (along with a path diagram included specifically to assess possible mediation) was depicted explaining the conceptual relational chain (see Figure 1). This model assumes a three-variable system where there are two relational paths feeding into the outcome variable: the direct impact of the predictor variable $(\mathrm{SL})$ on the predicted variable $(\mathrm{H} \& \mathrm{O})$ as Path", with the impact of the mediator (TBL - Path $\left.{ }^{\ddagger}\right)$ on the relationship between SL and H\&O.

Mediation was assessed by focusing on the indirect effect of SL on H\&O, by means of bootstrapping (95\% confidence interval [CI]), as recommended by Hayes and Rockwood (2017), conducted with SPSS PROCESS.

Finally, as surveys (self-reporting) were used as data source and given that all were administered at the same time, common method bias $(\mathrm{CMB})$ might be present. It was deemed necessary to determine firstly the presence of $\mathrm{CMB}$, and secondly the nature and magnitude thereof, all of which might impact on the relationship between the constructs under investigation. This was done by means of the inclusion of an unrelated, MV, namely SD. Social desirability, according to Crowne and Marlow (1964), entails responding to measurement items in a distorted manner. It is often regarded to be part of human nature, specifically as a focus on self-interest, also referred to as 'faking good' by Crowne and Marlowe (1960). Podsakoff, MacKenzie, Lee and Podsakoff (2003, p. 893) regard SD as 'one of the most powerful causes of common method biases'. The rationale for the inclusion of $\mathrm{SD}$ as a $\mathrm{MV}$ is intended purely to control for $\mathrm{CMB}$, and not for any diagnostic purposes.

Social desirability was identified as MV as it is regarded to be a variable that does not have any hypothesised relationship with the three constructs under investigation in this study. A standard CFA marker approach, as described by Williams, Hartman and Cavazotte (2010) was followed. The process consists of four steps and is reported under the results section as such

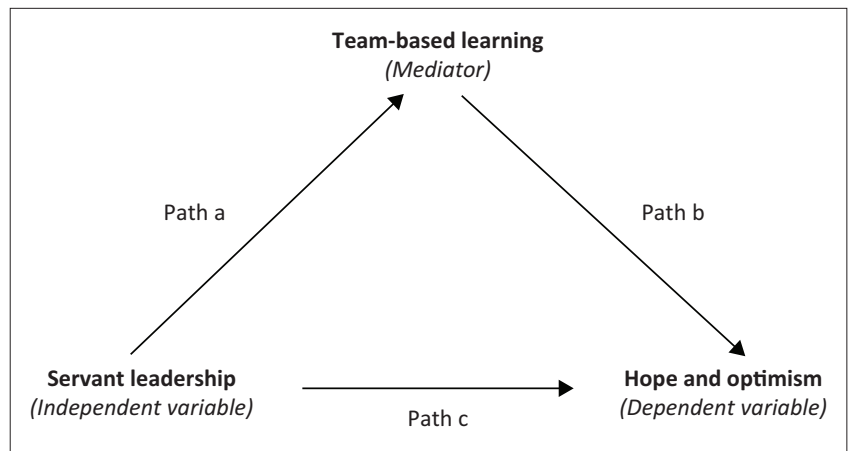

FIGURE 1: Mediation effect of team-based learning on the relationship between servant leadership and hope and optimism.

\section{Ethical considerations}

Ethical clearance was obtained from the University of South Africa's School of Business Leadership Research Ethics Review Committee. It includes permission from each organisation, the consent of all the participants as regards their participation in the study, and permission of all coresearchers for the primary researcher to make use of the data for research purposes.

\section{Results}

Firstly, the structural (construct) validity of the TBL instrument was assessed by means of an exploratory factor analysis (EFA), followed by a CFA after splitting the sample into two samples $(n=780)$, respectively. The EFA yielded acceptable values for the Bartlett test of sphericity with $p \leq 0.001$, which was higher than the set margin of $p<0.05$, and the Kaiser-Meyer-Olkin (KMO) measure (0.95), which is higher than the critical value of 0.60 . The Kaiser's criterion (K1 rule) and the interpretation of the scree-plot suggested a four-factor solution ( $65 \%$ of the total variance), but the more stringent process of the Monte Carlo parallel analysis, suggested a three-factor solution for the TBL instrument, accounting for $60 \%$ of the total variance in TBL. An oblique rotation method, specifically Promax rotation, was used and factor loadings ranged between 0.41 and 0.95 for items on the three factors. The criterion of a factor loading cut-off point of 0.50 for inclusion in the interpretation of a factor (Hair, Black, Babin, \& Anderson, 2010) resulted in all 14 of the original 20 items being included in the instrument with significant factor loadings on the three factors. Factor 1, Continued improvement philosophy, consisting of five of the original seven items (items six and seven of the original instrument by Bresó et al. ([2008] not included), Factor 2, Dialogue promotion and open communication, having five items, identical to the original instrument, and Factor 3, Strategic and proactive leadership that promote collaborative learning, consisting of four items, made up of a combination of the original dimensions of Collaborative learning and Strategic and proactive leadership that promote learning by Bresó et al. (2008).

The communalities ( $h 2)$ of the three factors were relatively high $(>0.50)$. The Cronbach alpha coefficients were acceptable ( $\alpha=0.85$ to $\alpha=0.87$, respectively) when the guideline of $\alpha>0.70$ (Tabachnick \& Fidell, 2013) was applied. The tolerance, as well as the Variance Inflation Factor (VIF) values, met the criteria ( $>0.10$, and $<10$, respectively) (Pallant, 2016) and therefore it can be concluded that there is no violation of the multicollinearity assumption.

The CFA confirmed the second-order model as the best fitting model. In this model, 14 items load directly on the three factors, respectively, that contribute to a secondary factor, namely TBL. The results indicated a good fit $\left(\chi^{2}=364\right.$, $d f=74, \chi^{2} / d f=4.92 ; p<0.001, I F I=0.98, T L I=0.97, C F I=0.98$, RMSEA $=0.050)$ for the combined sample, with comparable results for the two split samples. The analysis of the data 
obtained with the instruments used in this study can thus be done with confidence, as all three instruments are validated within the South African context. The descriptive statistics, as well as the psychometric properties of the instruments, are reported in Table 2 .

The Cronbach alpha coefficients of all the instruments (treated as unidimensional constructs), across the private and public sectors, as well as the combined sample, are acceptable (guideline of $\alpha>0.70$ ) (Tabachnick \& Fidell, 2013).

The descriptive statistics in Table 2 showed skewness and kurtosis values that did not exceed the critical values of two and seven, respectively (West, Finch, \& Curran, 1995). This is an indication that the data is normally distributed, allowing the continuation of the analysis by means of parametric statistical techniques. The skewness values are negative, which is an indication that the distribution has relatively few small values and tails off to the left. This resulted in relatively high mean scores on all the constructs. Higher mean scores were reported by the private sector scores on all three variables. $t$-tests were performed to determine the statistical significance of the differences between the mean scores across the two sectors. The results are reported in Table 3.

The results of the $t$-tests reported in Table 4 indicate, through the Levene's test, the variance of the two groups (private and public sector). Based on the significance values, it is assumed that equal variances between the two groups do not exist. The interpretation was done accordingly, with the results indicating that there are no statistically significant differences between sectors $(p<0.05)$.

TABLE 2: Descriptive statistics of the variables and reliability coefficients of the instruments (across the sectors).

\begin{tabular}{llccccc}
\hline Factor & Sector & Mean & $\begin{array}{c}\text { Standard } \\
\text { deviation }\end{array}$ & Skewness & Kurtosis & $\boldsymbol{\alpha}$ \\
\hline SL & Private sector & 4.57 & 1.23 & -0.39 & -0.29 & 0.83 \\
& Public sector & 4.50 & 1.37 & -0.45 & -0.49 & 0.91 \\
& Combined sample & 4.54 & 1.30 & -0.43 & -0.37 & 0.87 \\
TBL & Private sector & 4.23 & 0.81 & -0.56 & 0.21 & 0.91 \\
& Public sector & 4.18 & 0.89 & -0.74 & 0.34 & 0.94 \\
& Combined sample & 4.20 & 0.85 & -0.67 & 0.33 & 0.93 \\
H\&O & Private sector & 4.62 & 0.80 & -0.64 & 0.26 & 0.80 \\
& Public sector & 4.60 & 0.74 & -0.57 & 0.68 & 0.84 \\
& Combined sample & 4.61 & 0.77 & -0.61 & 0.45 & 0.82 \\
\hline
\end{tabular}

SL, Servant leadership; TBL, Team-based learning; H\&O, Hope and optimism.
The correlation coefficients between the variables, for the combined group as well as for the sectors separately, are reported in Table 4. The statistical differences between the correlations, in terms of the Fisher r-to-z transformation, are also reported.

After inspection of Table 4, it is evident that all correlations are significant at $p \leq 0.001$ levels and ranged between 0.39 and 0.72. Consistently, across all sectors and the combined group, the highest correlations were for SL and TBL (ranging from 0.56 to 0.72 ). In analysing the correlations of the three variables across the two sectors, it was found that the correlation between SL and TBL, as well as between TBL and H\&O, differed significantly $\left(-1.96 \leq z_{\text {obs }} \geq 1.96\right)$, with the private sector reporting a correlation of $r_{\mathrm{a}}=0.76$ and 0.58 compared to the public sector's $r_{\mathrm{b}}=0.56$ and 0.41 on the respective constructs (all $p \leq 0.001$ ). The correlations between the MV and the constructs are discussed under the section concerned with the assessment of CMB.

A hierarchical regression analysis was conducted to determine the extent to which SL and TBL explained the variance in TBL. The analysis was again conducted on the combined group, as well as on the sectors separately. The results are reported in Tables 5 and 6 .

The hierarchical regression analysis conducted on the total sample yielded a multiple regression coefficient of 0.26 . Servant leadership and TBL thus explain $26 \%$ of the variance in $\mathrm{H} \& \mathrm{O}(p \leq 0.001)$. This converts to a practical significance of $f^{2}=0.35$ (medium effect). It seems, after the inspection of the sectoral results in Table 5, that SL and TBL has a large effect $\left(f^{2}=0.49\right)$ (Cohen, 1988) on $\mathrm{H} \& \mathrm{O}(33 \%$ of the variance explained) in the private sector $(p \leq 0.001)$.

TABLE 4: Correlation between servant leadership, team-based learning and hope and optimism, the significance of the differences in the correlations, and the marker variable.

\begin{tabular}{lcccc}
\hline Factors & $\begin{array}{c}\text { Private sector } \\
(\boldsymbol{r}+)\end{array}$ & $\begin{array}{c}\text { Public sector: } \\
(\boldsymbol{r}+)\end{array}$ & $\begin{array}{c}\text { Combined } \\
\text { sample }\end{array}$ & $\begin{array}{c}\text { Fisher } \\
\text { z-observed }+\$\end{array}$ \\
\hline $\mathrm{SL}-\mathrm{TBL}$ & 0.72 & 0.56 & 0.63 & $5.42^{*}$ \\
$\mathrm{SL}-\mathrm{H} \& \mathrm{O}$ & 0.44 & 0.39 & 0.41 & 1.19 \\
$\mathrm{TBL}-\mathrm{H} \& \mathrm{O}$ & 0.58 & 0.41 & 0.49 & $4.47^{*}$ \\
$\mathrm{MV}-\mathrm{SL}$ & - & - & -0.05 & - \\
$\mathrm{MV}-\mathrm{TBL}$ & - & - & 0.02 & - \\
$\mathrm{MV}-\mathrm{H} \& \mathrm{O}$ & - & - & -0.04 & - \\
\hline
\end{tabular}

SL, Servant leadership; TBL, Team-based learning; H\&O, Hope and optimism; MV, Marker variable.

$\dagger$, private sector correlations; $\uparrow$, public sector correlations.

*, Significance.

TABLE 3: $t$-test (between group differences) with sector as grouping variable and servant leadership, team-based learning and hope and optimism.

\begin{tabular}{|c|c|c|c|c|c|c|c|c|}
\hline \multirow[t]{2}{*}{ Factor } & \multirow[t]{2}{*}{ Equal variances } & \multicolumn{2}{|c|}{ Levene's test for equality of variances } & \multicolumn{5}{|c|}{$t$-test for equality of means } \\
\hline & & $F$ & Significance & $t$ & $d f$ & $\begin{array}{c}\text { Significance } \\
\text { (2-tailed) }\end{array}$ & Mean difference & $\begin{array}{l}\text { Standard error } \\
\text { difference }\end{array}$ \\
\hline \multirow[t]{2}{*}{ SL } & Assumed & 10.41 & 0.01 & 1.07 & 1558 & 0.29 & 0.07 & 10.41 \\
\hline & Not assumed & - & - & 1.07 & 1540 & 0.29 & 0.07 & - \\
\hline \multirow[t]{2}{*}{ TBL } & Assumed & 6.47 & 0.01 & 1.21 & 1558 & 0.23 & 0.05 & 6.47 \\
\hline & Not assumed & - & - & 1.21 & 1544 & 0.23 & 0.05 & - \\
\hline \multirow[t]{2}{*}{$\mathrm{H} \& \mathrm{O}$} & Assumed & 4.01 & 0.05 & 0.41 & 1558 & 0.68 & 0.02 & 4.01 \\
\hline & Not assumed & - & - & 0.41 & 1549 & 0.68 & 0.02 & - \\
\hline
\end{tabular}

SL, Servant leadership; TBL, Team-based learning; H\&O, Hope and optimism. 
The relative strength of the contribution of each of the predictor variables (in terms of its beta coefficients) is reported in Table 6 .

The results in Table 6 indicate that the contribution of TBL in the explanation of variance in $\mathrm{H} \& \mathrm{O}$ is relatively higher compared to SL, with higher beta values $(\beta=0.54, \beta=0.28$ and $\beta=0.39$ (all at $p \leq 0.001$ ) for the private and public sectors, and the combined group, respectively. This is in comparison with the contribution of SL in the multiple regression with beta values of $\beta=0.05, \beta=0.23$ and $\beta=0.17$ (all at $p \leq 0.001$ ) for the two respective sectors and the combined group. This suggests that SL is regarded to be more important to the public sector as regards $\mathrm{H} \& \mathrm{O}$, compared to the private sector $\beta=0.23$ compared to $\beta=0.05$, respectively).

Although the values are not included in the previous tables, non-multicollinearity was found after inspection of the VIF $(<10)$ and the tolerance values $(>0.10)$ (Pallant, 2016). The instruments can, therefore, be used independently.

\section{Mediation analysis}

One of the objectives of this study was to determine the influence (mediation) of TBL on the relationship between SL (as predictor variable) and $\mathrm{H} \& \mathrm{O}$ (as outcome variable) using bootstrapping $(95 \% \mathrm{CI})$, as recommended by Hayes and Rockwood (2017). The results of the mediation analysis (using SPSS PROCESS) are depicted in Figure 2.

The results, as depicted in Figure 2, indicate that SL affected $\mathrm{H} \& \mathrm{O}$ by 0.24 , and TBL by 0.35 , for the combined group. Similar results were reported for the sectors, with 0.28 , and 0.54 for the private sector and 0.21 and 0.24 for the public sector, respectively (all significant at $p \leq 0.001$ ).

TABLE 5: Model summary of regression analysis - Variance explained in hope and optimism by team-based learning and servant leadership.

\begin{tabular}{lccccccc}
\hline Sector & Model & $\mathbf{R}$ & $\boldsymbol{R}^{2}$ & $\begin{array}{c}\text { Adjusted } \\
\boldsymbol{R}^{2}\end{array}$ & $\begin{array}{c}\text { Standard } \\
\text { error }\end{array}$ & $\boldsymbol{R}^{2}$ change & $\begin{array}{c}\text { Significance } \\
(\boldsymbol{p})\end{array}$ \\
\hline Private & - & - & - & - & - & 0.14 & - \\
sector & $\dagger$ & 0.44 & 0.19 & 0.19 & 0.72 & - & $\leq 0.001$ \\
& $\dagger$ & 0.58 & 0.34 & 0.33 & 0.65 & - & $\leq 0.001$ \\
& - & - & - & - & - & 0.05 & - \\
Public & $\dagger$ & 0.39 & 0.15 & 0.15 & 0.69 & - & $\leq 0.001$ \\
sector & $\dagger$ & 0.45 & 0.21 & 0.20 & 0.66 & - & $\leq 0.001$ \\
& - & - & - & - & - & 0.09 & - \\
Combined & - & 0.41 & 0.17 & 0.17 & 0.70 & - & $\leq 0.001$ \\
sample & $\dagger$ & & & \\
& $\dagger$ & 0.51 & 0.26 & 0.26 & 0.67 & - & $\leq 0.001$ \\
\hline
\end{tabular}

Note: Dependent variable: H\&O.

$\dagger$, Independent variables: (Constant), SL; + , Independent variables: (Constant), SL and TBL.

TABLE 6: Unique contributions of predictors to variance in hope and optimism (only standardised coefficients are presented).

\begin{tabular}{lcccccccc}
\hline Factor & \multicolumn{2}{c}{ Private sector } & & \multicolumn{2}{c}{ Public sector } & & \multicolumn{2}{c}{ Combined sample } \\
\cline { 2 - 3 } & $\boldsymbol{\beta}$ & $\boldsymbol{t}$ & & $\boldsymbol{B}$ & $\boldsymbol{t}$ & & $\boldsymbol{\beta}$ & $\boldsymbol{t}$ \\
\hline Constant & - & 17.59 & & - & 26.31 & & - & 31.33 \\
SL & 0.05 & 1.14 & & 0.23 & 5.89 & & 0.17 & 5.87 \\
TBL & 0.54 & 12.94 & & 0.28 & 7.36 & & 0.39 & 13.79 \\
\hline
\end{tabular}

Note: Independent variables: (constant) Dependent variable: H\&O; all $p \leq 0.001$.

SL, Servant leadership; TBL, Team-based learning.
A significant indirect effect (mediation) of SL on $\mathrm{H} \& \mathrm{O}$ through TBL was also reported for the combined sample, with $a b=0.15(0.12,0.17)$. A slightly higher indirect effect was reported for the private sector $(0.25[0.21,0.29])$, compared to the public sector $(0.09[0.08,0.15])$. The percentages of the total effect (c) that are accounted for by the indirect effect $(\mathrm{a} * \mathrm{~b})$ are $63 \%$ for the combined sample and $89 \%$ and $43 \%$ for the private and public sectors, respectively.

Test for CMB was conducted on the combined sample. Firstly, drawn from the information in Table 4, it is evident that relatively strong correlation coefficients exist between the constructs under investigation (ranging between $r=0.41$ and $r=0.63$ ). Questions of possible CMB may arise as a result of the cognate nature of the constructs under investigation, as well as the use of similar measurement methodologies. A very small, insignificant correlation between the MV and SL, TBL and $\mathrm{H} \& \mathrm{O}$ (ranging from $r=-0.05$ to $r=0.02$ ) is reported, which is a prerequisite for the use of a MV in the determination of $\mathrm{CMB}$. The results of the CFA, with the inclusion of $\mathrm{SD}$ as a $\mathrm{MV}$, are reported in Table 7.

To determine the presence of CMB, three CFA models, consisting of the three variables under investigation and a $\mathrm{MV}$, were compared. This comparison suggests that CMB is, to some extent, present (as method-C fits significantly better than the baseline model). Method-U fits significantly better than method-C, which is an indication that the $C M B$ is assumed to be congeneric. The results indicate however that the presence of $\mathrm{CMB}$ does not skew the observed relationships. This is derived from the non-statistical significant difference between method-R model-U (which reported better fit statistics compared to model-C).

\section{Discussion}

The world of work is changing and has changed more than expected because of the Covid-19 pandemic. Employees' well-being is even more important during challenging times such as these. The focus of this study was to determine the

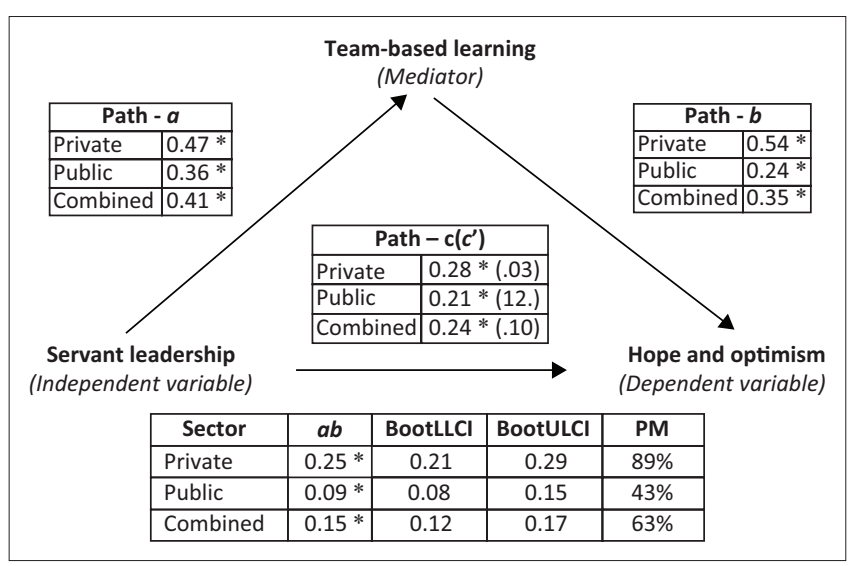

PM, Percentage mediation; LLCI, lower limit confidence interval; ULCI, upper limit confidence interval.

$*$, statistically significant $(p<0.05)$

FIGURE 2: Mediation effect of team-based learning on the relationship between servant leadership and hope and optimism. 
TABLE 7: Model fit indices and model comparisons for CFA models with marker variable (social desirability).

\begin{tabular}{|c|c|c|c|c|c|c|c|c|c|}
\hline \multirow[t]{2}{*}{ Model } & \multirow[t]{2}{*}{$\chi^{2}$} & \multirow[t]{2}{*}{$d f$} & \multirow[t]{2}{*}{ CFI } & \multirow[t]{2}{*}{ RMSEA } & \multirow[t]{2}{*}{$90 \% \mathrm{Cl}$} & \multicolumn{3}{|c|}{ LR } & \multirow[t]{2}{*}{ Model comparison } \\
\hline & & & & & & $\Delta \chi^{2}$ & $d f$ & $\rho$ & \\
\hline CFA with MV & 3683.61 & 521 & 0.864 & 0.062 & $0.061 ; 0.064$ & - & - & - & - \\
\hline Baseline & 3744.27 & 53 & 0.862 & 0.062 & $0.060 ; 0.064$ & - & - & - & - \\
\hline Method-C & 4177.60 & 535 & 0.844 & 0.066 & $0.064 ; 0.068$ & 433.33 & 1 & $\leq 0.001$ & versus baseline \\
\hline Method-U & 3410.79 & 508 & 0.875 & 0.061 & $0.059 ; 0.062$ & 766.81 & 27 & $\leq 0.001$ & versus method-C \\
\hline Method-R & 3411.37 & 511 & 0.876 & 0.060 & $0.058 ; 0.062$ & 0.58 & 3 & 0.99 & versus method-U \\
\hline
\end{tabular}

CFA, confirmatory factor analysis; MV, marker variable (social desirability); CFI, comparative fit index; RMSEA, root mean square error of approximation; LR, likelihood ratio test; $U$, unconstrained; $C$, constrained; $R$, restricted.

relationship between SL and $\mathrm{H} \& \mathrm{O}$ (as a core component of well-being), with the possible mediating role of TBL. Teambased learning was included in the model as it is regarded to be an important aspect during organisational change, which is currently inevitable, and as being part of the collective nature of the South African culture. The analysis included a comparison of the public sector along with the private sector, as context is regarded to be a differentiating factor, especially when leadership is studied.

Role modelling of leaders and team members and the reciprocal nature of the leadership relationship, as underpinned by the social learning and social exchange theories form the basis of the conceptualisation of this study, where the effect of SL on $\mathrm{H} \& \mathrm{O}$ (as individual and organisational behaviour outcome) was assessed.

All instruments used, except for the TBL instrument, were validated for the diverse, multi-lingual South African context. This study includes the validation of the TBL instrument. The results of the factor analysis (EFA as well as CFA, using a split sample), yielded a different factor structure (compared to the original instrument), with the fit indexes supporting the approach to use the total construct of TBL in the analysis.

Considering the descriptive statistics, all three constructs reported relatively high mean scores, with the scores for the private sector being slightly higher than those for the public sector. However, when comparing the sectors with each other in terms of the mean scores reported ( $t$-tests) on each of the constructs, no statistically significant differences $(p<0.05)$ were reported. In assessing the assumptions of the social learning and social exchange theories, it was found that leadership (specifically SL) and team processes (in this instance, TBL) influence $\mathrm{H} \& \mathrm{O}$ as individual component of the model. Strong correlations (of higher than 0.40) were reported, with slightly higher correlations for the private sector compared to the public sector. This supports the notion that leadership and the perception thereof has a lesser influence in the public sector, this because of the existence of leadership constraints and over-bureaucratisation of the public sector (Altwater \& Wright, 1996; Bourantas \& Papalexandris, 1993; Hansen \& Villadsen, 2010).

The results of the hierarchical regression analysis also support the conceptual model, with $26 \%$ of the variance in $\mathrm{H} \& \mathrm{O}$ (medium effect) explained by SL and TBL.
Slightly different results were reported for the two sectors when separate hierarchical regression analysis was performed. The private sector yielded stronger regression results compared to the public sector, with SL and TBL explaining 33\% of the variance in $\mathrm{H} \& \mathrm{O}$ (large effect), compared to the $20 \%$ in the public sector (medium effect). One possible explanation for this is that the public sector is often viewed as being more impersonal, managed (and not led), through strict rules and regulations.

When the relative importance of the two independent variables is compared, it was found that TBL (beta value of 0.54 ) is slightly more important in the model (than SL, beta value of 0.05 ), for both sectors but specifically the private sector. It was further found that the relationship between SL and $\mathrm{H} \& \mathrm{O}$ is mediated by TBL.

Lastly, the presence of $\mathrm{CMB}$ was investigated and it was found that, although there is evidence of $C M B$, it did not skew the observed relationships between the variables.

\section{Practical and managerial implications}

This study also has practical implications. Firstly, it provides further empirical evidence that SL is positively associated with H\&O. Thus, when employees feel valued and that an investment is being made in their future, they will be likely to be more persevering (Seligman \& Csikszentmihalyi, 2000), psychologically engaged, and more committed in a challenging environment. Secondly, the future-mindedness and future-orientation of $\mathrm{H} \& \mathrm{O}$ could stimulate adaptive responses during this time of uncertainty and turmoil. Thus, $\mathrm{H} \& \mathrm{O}$, as potential resilience factors, could generate resilience by harnessing opportunities and setbacks (Bailis \& Chipperfield, 2012) both during the Covid-19 pandemic and in its aftermath. From a leadership perspective, the study has implications for leadership protocols in organisations. Leaders and managers have the right to be uncertain, particularly during turbulent times. However, they must be clear in terms of how they lead. Servant leadership offers a compelling-yet-simple blueprint to serve others first, and to take authentic care of them with a firm emphasis on ethics and morality. The findings from the study suggest that SL and psychological capital (positive future orientation), in the form of $\mathrm{H} \& \mathrm{O}$, could be drivers of TBL to be leveraged by organisations in the interest of efficiency and performance. Organisations now have access to a validated TBL instrument, which can be used with confidence to help optimise team functioning within both the private and public sectors in South Africa. 


\section{Conclusion}

In summary, the results suggest that where employees perceive their leaders to be SL, they will have a more positive future orientation, and specifically being more hopeful and optimistic about the future. This could be further enhanced in the South African collectivistic culture by adopting a TBL strategy, with a philosophy of continuous improvement, dialogue, open communication and collaborative learning, as well as leadership that promotes learning, specifically during times of change and crisis.

\section{Limitations of the study and suggestions for future research}

This study was also not without limitations. Firstly, it used a cross-sectional design, which might have artificially inflated the relationship between the variables (Maxwell \& Cole, 2007). This means that no causal inferences concerning the associations between the variables can be drawn. Future research should investigate the relationship between the constructs through longitudinal research. A further recommendation is to conduct additional research by investigating the impact of demographic characteristics and other work-related attitudes and organisation behavioural constructs. The validated TBL instrument could also be used with confidence within the South African context.

\section{Acknowledgements}

The authors want to acknowledge the contribution of the coresearchers, who were MBA and MBL students.

\section{Competing interests}

The authors declare that they have no financial or personal relationships that may have inappropriately influenced them in writing this article.

\section{Authors' contributions}

A.G. coordinated the data collection process and conducted the data analysis. A.P.F. made contributions regarding the conceptualisation of the article, as well as writing and editing.

\section{Funding information}

This research received no specific grant from any funding agency in the public, commercial or not-for-profit sectors.

\section{Data availability}

The data are not publicly available. Only the primary researchers have access to the primary data as approved by the ethics committee.

\section{Disclaimer}

The views and opinions expressed in this article are those of the authors and do not necessarily reflect the official policy or position of any affiliated agency of the authors.

\section{References}

Altwater, L.E., \& Wright, W.J. (1996). Power and transformational and transactional leadership in public and private organizations. Internationa Journal of Public Administration, 19(6), 963-989. https://doi. org/10.1080/01900699608525127

Anestis, M.D., Moberg, F.B., \& Amau, R.C. (2014). Hope and the interpersonalpsychological theory of suicidal behaviour: Replication and extension of prior findings. Suicide and Life-Threatening Behaviour, 44(2), 175-187. https://doi. org/10.1111/sltb.12060

Bailis, D.S., \& Chipperfield, J.G. (2012). Hope and optimism. Health Psychology, 24(4), 393-401. https://doi.org/10.1037/0278-6133.24.4.393

Bandura, A. (1977). Social learning theory. Englewood Cliffs, NJ: Prentice-Hall.

Barsade, S.G. (2002). The ripple effect: Emotional contagion and its influence on group behaviour. Administrative Science Quarterly, 47(4), 644-675. https://doi. org/10.2307/3094912

Bedi, A., Alpaslan, C.M., \& Green, S. (2016). A meta-analytic review of ethical leadership outcomes and moderators. Journal of Business Ethics, 139, 517-536. https://doi.org/10.1007/s10551-015-2625-1

Bergh, Z., \& Geldenhuys, D. (2014). Psychology in the work context (5th edn.). Cape Town: Oxford University Press Southern Africa.

Blau, P.M. (1964). Exchange and power in social life. New York, NY: Wiley.

Bourantas, D., \& Papalexandris, N. (1993). Differences in leadership behaviour and influence between public and private organizations in Greece. The Internationa Journal of Human Resource Management, 4(4), 859-871. https://doi. org/10.1080/09585199300000061

Bouzari, M., \& Karatepe, O.M. (2017). Test of a mediation model of psychological capital among hotel salespeople. International Journal of Contemporary Hospitality Management, 29(8), 2178-2197. https://doi.org/10.1108/ IJCHM-01-2016-0022

Bresó, I., Garcia, F.J., Latorre, F.E., \& Peiró, J.M. (2008). Development and validation of the team learning questionnaire. Comportamento Organizacional E Gestão, 14(2), 145-160.

Chen, Z., Zhu, J., \& Zhou, M. (2015). How does a servant leader fuel the service fire? A multilevel model of servant leadership, individual self-identity, group competition climate, and customer service performance. Journal of Applied Psychology, 100(2), 511-521. https://doi.org/10.1037/a0038036

Cohen, J. (1988). Statistical analysis for behavioural sciences (2nd edn.). Hillsdale, NJ: Erlbaum.

Crowne, D.P., \& Marlowe, D. (1960). A new scale of social desirability independent of psychopathology. Journal of consulting Psychology, 24(4), 349-354. https://doi. org/10.1037/h0047358

Crowne, D.P., \& Marlowe, D. (1964). The approval motive: Studies in evaluative dependence. New York, NY: John Wiley.

Cvitanovic, C., \& Hobday, A.J. (2018). Building optimism at the environmental sciencepolicy-practice interface through the study of bright spots. Nature Communications, 9, 3466. https://doi.org/10.1038/s41467-018-05977-w

Davis, L.J. (2018). The relationship between servant leadership and psychological capital: A follower's perspective. Unpublished PhD thesis. Kent State University.

Deloitte. (2019). 2019 Deloitte global human capital trends Leading the social enterprise: Reinvent with human focus. Retrieved from https://www2.deloitte. com/za/en/pages/human-capital/articles/2019-deloitte-global-human-capitaltrends-.html

Dennis, R.S., \& Bocarnea, M. (2005). Development of the servant leadership assessment instrument. Leadership \& Organization Development Journal, 26(8), 600-615. https://doi.org/10.1108/01437730510633692

Diamond, M.A. (2016). Discovering organizational identity: Dynamics of relationa attachment. Missouri, MO: University of Missouri Press.

Ebright, P.R., \& Lyon, B. (2002). Understanding hope and factors that enhance hope in women with breast cancer. Oncology Nursing Forum, 29(3), 561-568. https://doi. org/10.1188/02.ONF.561-568

Edmonson, A. (1999). Psychological safety and learning behaviour in work teams. Administrative Science Quarterly, 44(2), 350-383. https://doi.org/10.2307/2666999

Edmonson, A. (2002). The local and variegated nature of learning in organizations: A group-level perspective. Organization Science, 13(2), 128-146. https://doi. org/10.1287/orsc.13.2.128.530

Ellis, A.P., Hollenbeck, J.R., Ilgen, D.R., Porter, C.O., West, B.J., \& Moon, H. (2003) Team learning: Collectively connecting the dots. Journal of Applied Psychology, 88(5), 821-835. https://doi.org/10.1037/0021-9010.88.5.821

Eva, N., Robin, M., Sendjaya, S., Van Dierendonck, D., \& Liden, R.C. (2019). Servant leadership: A systematic review and call for future research. Leadership Quarterly, 30(1), 111-132. https://doi.org/10.1016/j.leaqua.2018.07.004

Farling, M.L., Stone, G.A., \& Winston, B.E. (1999). Servant leadership: Setting the stage for empirical research. Journal of Leadership Studies, 6(1-2), 49-672. https://doi. org/10.1177/107179199900600104

Felder, B.E. (2004). Hope and coping in patients with cancer diagnoses. Nursing Studies, 27(4), 320-324. https://doi.org/10.1097/00002820-200407000-00009

Flotman, A.P., May, M.S., \& Cilliers, F. (2019). Language as potential space for relational positioning: Exploring language use as manifestation of leadership anxiety dynamics. Journal of Psychology in Africa, 29(1), 80-83. https://doi.org/10.1080/ 14330237.2019.1568002

Graham, J. (1991). Servant leadership in organizations: Inspirational and moral. Leadership Quarterly, 2(2), 105-119. https://doi.org/10.1016/1048-9843(91)90025-W 
Greenleaf, R.K. (1977). Servant leadership: A journey into the nature of legitimate power and greatness. Mahwah, NJ: Paulist Press.

Grobler, A., \& Flotman, A.P. (2020). The validation of the servant leadership scale from an Afrocentric perspective. SA Journal of Industrial Psychology/SA Tydskrif vir Bedryfsielkunde, 46(0), a1754. https://doi.org/10.4102/sajip.v46i0.1754

Grobler, A., \& Joubert, Y.T. (2020). Hope and optimism, ethical leadership and fit perceptions. South African Journal of Economic and Management Sciences, 23(1) a2872. https://doi.org/10.4102/sajems.v23i1.2872

Grobler, A., \& Mathafena, R.B. (2020). Assessing the dimensionality of three LMX instruments within a diverse cultural and linguistic context. Psihologija, 54(1),33-48. https://doi.org/10.2298/PSI191011019G

Grobler A., \& Singh, V. (2018). Leadership in Southern Africa: A regional Afrocentric hierarchical taxonomy. Insight on Africa, 10(2), 1-25. https://doi. org $/ 10.1177 / 0975087818772236$

Hair, J.F., Black, W.C., Babin, B.J., \& Anderson, R.E. (2010). Multivariate data analysis: A global perspective (7th edn.). Boston, MA: Pearson.

Hansen, J.R., \& Villadsen, A.R. (2010). Comparing public and private managers' leadership styles: Understanding the role of job context. International Public Management Journal, 13(3), 247-274. https://doi.org/10.1080/10967494.2010.5 03793

Haranath, G. (2017). A comparative study of leadership styles in select public and private sector organizations. Finance India, 2, 575-578.

Hayes, A.F., \& Preacher, K.J. (2014). Statistical mediation analysis with a multicategorical independent variable. British Journal of Mathematical and Statistical Psychology, 67(3), 451-470. https://doi.org/10.1111/bmsp.12028

Hayes, A.F., \& Rockwood, N.J. (2017). Regression-based statistical mediation and moderation analysis in clinical research: Observations, recommendations, and implementation. Behaviour Research and Therapy, 98, 39-57. https://doi. org/10.1016/j.brat.2016.11.001

Hersey, P., \& Blanchard, H.K. (1969). Life cycle theory of leadership. Training and Develop Journal, 23(5), 26-34.

House, R.J. (1971). A path goal theory of leader effectiveness. Administrative Science Quarterly, 16(3), 321-338. https://doi.org/10.2307/2391905

Huen, J.M.Y., Ip, B.Y.T., Ho, S.M.Y., \& Yip, P.S.F. (2015). Hope and hopelessness: The role of hope in buffering the impact of hopelessness on suicidal ideation. PLos One 10(6), 1-18. https://doi.org/10.1371/journal.pone.0130073

Hu, L.T., \& Bentler, P.M. (1999). Cut-off criteria for fit indexes in covariance structure analysis: Conventional criteria versus new alternatives. Structural Equation Modeling, 6(1), 1-55. https://doi.org/10.1080/10705519909540118

IBM Corp. (2017). IBM SPSS statistics for windows, version 25.0. Armonk, NY: IBM Corp.

Johns, L.N., \& Jaquet, J. (2018). Doom and gloom versus optimism: An assessment of ocean-related US science journalism. Global Environmental Change, 50, 142-148. https://doi.org/10.1016/j.gloenvcha.2018.04.002

Kasl, E., Marsick, V.J., \& Dechant, K. (1997). Teams as learners: A research-based model of team learning. Journal of Applied Behavioral Science, 33(2), 227-246. https://doi.org/10.1177/0021886397332010

Khuntia, R., \& Suar, D. (2004). A scale to assess ethical leadership of Indian private and public sector managers. Journal of Business Ethics, 49, 13-26. https://doi. org/10.1023/B:BUSI.0000013853.80287.da

Laub, J. (2004). Defining servant leadership: A recommended typology for servant leadership studies. In proceedings of servant leadership research roundtable (pp. 1-12). August 2-3, 2004, Virginia Beach, VA: Regent University, School of Leadership Studies.

Lewis, L. (2019). Organizational change: Creating change through strategic communication (2nd edn.). Hoboken, NJ: Wiley.

Liden, R.C., Wayne, S.J., Meuser, J.D., Hu, J., Wu, J., \& Liao, C. (2015). Servant leadership: Validation of a short form of the SL-28. Leadership Quarterly, 26(2), 254-269. https://doi.org/10.1016/j.leaqua.2014.12.002

Liden, R.C., Wayne, S.J., Zhao, H., \& Henderson, D. (2008). Servant leadership: Development of a multidimensional measure and multi-level assessment. Leadership Quarterly, 19(2), 161-177. https://doi.org/10.1016/j. leaqua.2008.01.006

Luthans, F., Norman, S.M., Avolio, B.J., \& Avey, J.B. (2008). The mediating role of psychological capital in the supportive organizational climate: Employe performance relationship. Journal of Organisational Behavior, 29(2), 219-238. https://doi.org/10.1002/job.507

Luthans, F., Youssef, C.M., \& Avolio, B.J. (2007). PsyCap: Developing the human competitive edge. Oxford: Oxford University Press.

Mahembe, B., \& Engelbrecht, A.S. (2013). A confirmatory factor analytical study of a servant leadership measure in South Africa. SA Journal of Industrial Psychology/ SA Tydskrif vir Bedryfsielkunde, 39(2), Art. \#1127, 8 pages. https://doi org/10.4102/sajip.v39i2.1127

Maxwell, S.E., \& Cole, D.A. (2007). Bias in cross-sectional analyses of longitudinal mediation. Psychological Methods, 12(1), 23-44. https://doi.org/10.1037/1083989X.12.1.23

Mcafee, D., Doubleday, Z.A., Geiger, N., \& Connell, S.D. (2019). Everyone loves a success story: Optimism inspires conservation engagement. Bioscience, 69(4), 274-281. https://doi.org/10.1093/biosci/biz019

Mihalits, D.S., \& Codenotti, M. (2020). The conceptual tragedy in studying defense mechanisms. Integrated Psychological Behavioral Science, 54, 354-369. https:// doi.org/10.1007/s12124-020-09515-6
Orazi, D.C., Turrini, A., \& Valotti, G. (2013). Public sector leadership: New perspectives for research and practice. International Review of Administrative Sciences, 79(3), 486-504. https://doi.org/10.1177/0020852313489945

Ospina, S.M. (2016). Collective leadership and context in public administration: Bridging public leadership research and leadership studies. Public Administration Review, 77(2), 275-287. https://doi.org/10.1111/puar.12706

Pallant, J. (2016). SPSS survival manual: A step-by-step guide to data analysis using IBM SPSS (6th edn.). London: McGraw-Hill Education.

Parris, D.L., \& Peachey, J.W. (2013). A systematic literature review of servant leadership theory in organizational contexts. Journal of Business Ethics, 113, 377-393. https://doi.org/10.1007/s10551-012-1322-6

Patterson, K. (2003). Servant leadership: A theoretical model. In proceedings of the servant leadership roundtable. Retrieved from http://www.regent.edu

Peterson, S.J., \& Seligman, M. (2003). The positive impact and development of hopeful leaders. Leadership and Organization Development Journal, 24(1/2), 26-31. https://doi.org/10.1108/01437730310457302

Petriglieri, G. (2020). $\mathrm{F}^{* * \mathrm{k}}$ science!? An invitation to humanize organization theory. Organisation Theory, 1(1), 1-18. https://doi.org/10.1177/2631787719897663

Podsakoff, P.M., MacKenzie, S.B., Lee, J.Y., \& Podsakoff, N.P. (2003). Common method biases in behavioural research: A critical review of the literature and recommended remedies. Journal of Applied Psychology, 88(5), 879-903. https://doi. org/10.1037/0021-9010.88.5.879

Rajandram, R.K., Ho, S.M.Y., Samman, N., Chan, N., McGrath, C., \& Zwahlen, R. (2011). Interaction of hope and optimism with anxiety and depression in a specific group of cancer survivors: A preliminary study. Research Notes, 4, 519. https://doi. org/10.1186/1756-0500-4-519

Schiavon, C.C., Marchetti, E., Gurgel, L.G., Busnello, F.M., \& Reppold, C.T. (2017) Optimism and hope in chronic disease: A systematic review. Frontiers in Psychology, 7, 2022. https://doi.org/10.3389/fpsyg.2016.02022

Schumacker, R.E., \& Lomax, R.G. (1996). A beginner's guide to structural equation modelling. Mahwah, NJ: Lawrence Erlbaum Associates.

Seligman, M.E.P. (2008). Positive health. Applied Psychology, 57(S1), 3-18. https:// doi.org/10.1111/j.1464-0597.2008.00351.x

Seligman, M.E., \& Csikszentmihalyi, M. (2000). Positive psychology: An introduction. American Psychologist, 55(1), 5-14. https://doi.org/10.1037/0003-066X.55.1.5

Sendjaya, S., \& Sarros, J. (2002). Servant leadership: Its origin, development, and application in organizations. Journal of Leadership and Organizational Studies, 9(2), 57-64. https://doi.org/10.1177/107179190200900205

Sendjaya, S., Sarros, J.C., \& Santora, J.C. (2008). Defining and measuring servant leadership behaviour in organizations. Journal of Management Studies, 45(2), 402-424.

Senge, P.M. (1990). The fifth discipline: The art \& practice of the learning organisation. New York, NY: Doubleday.

Snyder, C.R. (2002). Hope theory: Rainbows in the mind. Psychological Inquiry, 13(4), 249-275. https://doi.org/10.1207/S15327965PLI1304_01

Song, C., Park, K.R., \& Kang, S.-W. (2015). Servant leadership and team performance: The mediating role of knowledge-sharing climate. Social Behavior and Personality: An International Journal, 43(10), 1749-1760. https://doi.org/10.2224/ sbp.2015.43.10.1749

Spears, L.C. (1998). Introduction: Tracing the past, present and future of servantleadership. In L.C. Spears (Ed.), Focus on leadership (pp. 1-18). New York, NY: John Wiley.

Spears, L.C. (2010). The character and servant leadership: Ten characteristics of effective, caring leaders. Journal of Virtues \& Leadership, 1(1), 25-30.

Strahan, R., \& Gerbasi, K.C. (1972). Short, homogeneous versions of the MarloweCrowne social desirability scale. Journal of Clinical Psychology, 28(2), 191-193. https://doi.org/10.1002/1097-4679(197204)28:2\%3C191::AIDJCLP2270280220\%3E3.0.CO;2-G

Swim, J.K., Geiger, N., Sweetland, J., \& Fraser, J. (2018). Social construction of scientifically grounded climate change discussions. London: Elsevier.

Tabachnick, B.G., \& Fidell, L.S. (2013). Using multivariate statistics (6th edn.). Boston, MA: Pearson.

Uhl-Bien, M., Maslyn, J., \& Ospina, S.M. (2012). The nature of relational leadership: Multi-theoretical lenses on leadership relationships and process. In D.V. Day \& J. Antonakis (Eds.), The nature of leadership (2nd edn., pp. 289-330). London Sage.

Vanacker, B., \& Heider, D. (2018). Ethics for a digital age. New York, NY: Peter Lang.

Van Dierendonck, D., \& Nuijten, I. (2011). The servant-leadership survey (SLQS): Development and validation of a multidimensional measure. Journal of Business and Psychology, 26(3), 249-267. https://doi.org/10.1007/s10869010-9194-1

Van Offenbeek, M. (2001). Processes and outcomes of team learning. European Journal of Work and Organizational Psychology, 10(3), 303-317. https://doi. org/10.1080/13594320143000690

Wallace, M., \& Tomlinson. M. (2010). Contextualizing leader dynamics: How public service leaders endeavour to build influence. Leadership, 6(1), 21-45. https://doi. org/10.1177/1742715009354238

West, S.G., Finch, J.F., \& Curran, P.J. (1995). Structural equation models with nonnormal variables: Problems and remedies. In R.H. Hoyle (Ed.), Structural equation modelling: Concepts, issues and applications (pp. 56-75). Thousand Oaks, CA: Sage. 
Williams, L.J., Hartman, N., \& Cavazotte, F. (2010). Method variance and marker variables: A review and comprehensive CFA marker technique. Organizational variables. A review and comprehensive CFA marker technique. Organizational 110366036

Wong, P.T.P., \& Page, D. (2003). Servant leadership: An opponent process model and the revised servant leadership profile. In proceedings of the servant leadership roundtable, Retrieved from http://www.regent.edu
Yeo, R. (2003). Linking organisational learning to organisational performance and success: Singapore case studies. Leadership \& Organization Development Journal, 24(1-2), 70-83. https://doi.org/10.1108/01437730310463260

Yoshida, D.T., Sendjaya, S., Hirst, G., \& Cooper, B. (2014). Does servant leadership foster creativity and innovation? A multi-level mediation study of identification and prototypicality. Journal of Business Research, 67(7), 1395-1404. https://doi. org/10.1016/j.jbusres.2013.08.013 